\title{
Diurnal ventilation via mouthpiece: survival in end-stage Duchenne patients
}

\author{
M. Toussaint, M. Steens, G. Wasteels and P. Soudon
}

ABSTRACT: The present study aimed to assess the impact of diurnal mouthpiece intermittent positive pressure ventilation (MIPPV) as the extension of the nasal intermittent positive pressure ventilation (NIPPV) in Duchenne muscular dystrophy (DMD). In total, 42 DMD patients aged 15-33 yrs, normocapnic at night with NIPPV and receiving MIPPV since end-diurnal hypercapnia, were studied.

Transcutaneous $\mathrm{CO}_{2}$ tension $\left(\mathrm{Pt}_{\mathrm{t}} \mathrm{CO}_{2}\right)$ was prospectively monitored at the end of the day, before and after MIPPV initiation. Vital capacity (VC), breathing pattern and maximal inspiratory strength were measured. Patients were asked to score the presence (1 point) or absence ( 0 point) of seven respiratory-linked symptoms before and after MIPPV establishment.

Survival rates reached $88,77,58$ and $51 \%$ after $1,3,5$ and 7 yrs, respectively. The mean survival rate was 31 yrs. VC stabilised during 5 yrs with MIPPV. Symptom scores significantly decreased and $\mathrm{Pt}_{\mathrm{t}} \mathrm{CO}_{2}$ normalised during the day $(8.17 \pm 2.22$ to $5.78 \pm 0.73 \mathrm{kPa})$. No accident and minor sideeffects were observed in this 184 cumulated patient-yrs study.

In conclusion, daytime mouthpiece ventilation is safe, prolongs survival and stabilises vital capacity in Duchenne muscular dystrophy patients. It is recommended on the condition that patients are equipped with a self-supporting harness.

KEYWORDS: Duchenne, mouthpiece, neuromuscular, noninvasive, survival, ventilation

$\mathbf{R}$ espiratory insufficiency appears in the course of Duchenne muscular dystrophy (DMD), first during sleep [1] and then at a later stage during the day [2]. With progressive respiratory failure, ventilation needs to be assisted. Invasive or noninvasive assisted mechanical ventilation are successful treatment options [3]. The duration and settings of ventilation aim at achieving optimal blood gases throughout the day. Nasal intermittent positive pressure ventilation (NIPPV) at night initially produces 24-h effective blood-gas improvement for several years [4]. In end-stage DMD patients, however, nocturnal NIPPV needs to be progressively used during the daytime as increasing ventilatory dependency develops [5]. Currently, tracheostomy is proposed in many countries due to the expense of complications and social disability [6]. However, when offered the choice, patients prefer noninvasive ventilation techniques [7]. One option for prolonging NIPPV in the daytime is the use of the nasal mask, which may interfere with the patient's social activity. Assisted ventilation during the day using mouthpiece intermittent positive pressure ventilation (MIPPV) is another, as yet, poorly explored

For editorial comments see page 468 . option. Historically, it originated in 1957 for daytime ventilation and in 1964 for nocturnal support in post-polio patients [6], and later in DMD patients [8]. Mouthpiece ventilation has been reported to be safe and comfortable for wheelchair use, aesthetic and easily applicable. It is inexpensive and confirmed as a user-friendly system during social activities, such as eating and speaking [9]. Surprisingly, this technology is not commonly used, and the long-term survival for daytime use is poorly documented in end-stage DMD patients [10]. It is empirically driven as no evidence-based guidelines exist as to when and how to start it. The aim of the present study was to investigate the feasibility of MIPPV as an extension of nocturnal NIPPV in DMD patients and the impact of establishing MIPPV on survival and on disease progression.

\section{MATERIAL AND METHODS \\ Patients}

From June 1, 1996 to December 31, 2005, 45 consecutive DMD patients, normocapnic at night with NIPPV, were considered for daytime MIPPV since they presented with additional diurnal hypercapnia. The patients were all wheelchair-bound before 12 yrs of age. The diagnosis of DMD was made according to the

\section{AFFILIATIONS}

Acute Neurorespiratory Rehabilitation Unit, Neuromuscular Excellency Centre VUB-Inkendaal and Centre for Home Mechanical Ventilation, Z.H. Inkendaal Rehabilitation Hospital, Brussels, Belgium.

CORRESPONDENCE M. Toussaint Acute Neurorespiratory Rehabilitation Unit

Neuromuscular Excellency Centre VUB-Inkendaal and Centre for Home Mechanical Ventilation

Z.H. Inkendaal Rehabilitation Hospital Inkendaalstraat 1

B-1602 Vlezenbeek Brussels

Belgium

Fax: 3225315301

E-mail: michel.toussaint@

inkendaal.be

Received:

January 132006

Accepted after revision:

June 162006
European Respiratory Journal Print ISSN 0903-1936 Online ISSN 1399-3003 
standard criteria available before 1998 [11]. All these patients benefited from home respiratory therapy by intrapulmonary percussive ventilation to prevent lower chest infections and to treat them at home when present [12]. The patients were trained in cough assistance techniques by abdominal-thoracic manual compression and by air-stacking mixed by experienced therapists from the Neuromuscular Excellency Centre (Brussels, Belgium). The efficiency of these techniques was assessed in all patients every 6 months by measurement of the peak expiratory cough flow improvement obtained during the manoeuvres. Mechanical cough assistance by Cough-Assist ${ }$ (Emerson, Cambridge, MA, USA) was available from 2002 for hospitalised patients and three $(7 \%)$ patients benefited from this technique at home from 2004. One patient had impaired cognitive level and two others had recurrent aspiration and ineffective cough, even when cough was assisted. All three underwent tracheostomy and were excluded from further analysis. The local ethics committee approved the ventilation protocol, and informed consent was obtained from the 42 DMD patients prior to study inclusion coinciding with MIPPV establishment.

\section{Study design}

The current prospective cohort study investigated the following: 1) the long-term impact of daytime MIPPV on survival and lung function; and 2) the short- and long-term impacts of daytime MIPPV on daytime $\mathrm{CO}_{2}$ tension and related symptoms.

\section{Ventilation protocol}

A strict protocol for mechanical ventilation was used (fig. 1), based on transcutaneous $\mathrm{CO}_{2}$ tension $\left(\mathrm{P}_{\mathrm{t}}, \mathrm{CO}_{2}\right)$ monitoring during sleep (22:00-07:00 h), followed by the monitoring of the last $2 \mathrm{~h}$ of the day in waking patients (20:00-22:00 h). Enddiurnal $\mathrm{Pt}_{\mathrm{t}} \mathrm{CO}_{2}$ concludes a full day of spontaneous respiration. It should assess the ability to sustain spontaneous ventilation during a full day [13]. Based on $\mathrm{Pt}_{\mathrm{t}} \mathrm{CO}_{2}$ measurements, ventilation prescription was decided by $\mathrm{P}$. Soudon, without knowledge of other test results.

In stage $0,24 \mathrm{~h}$ out of $24 \mathrm{~h}$ normocapnic patients were not ventilated (fig. 1a). In stage 1 , nasal NIPPV was introduced since nocturnal $\mathrm{Pt}_{\mathrm{t}} \mathrm{CO}_{2}$ was $>5.98 \mathrm{kPa}$, avoiding extension of nocturnal hypercapnia to the daytime with associated clinical deterioration (fig. 1b) [14]. Stage 2 was defined by end-diurnal

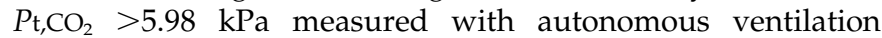
before resuming NIPPV (fig. 1c). Diurnal hypercapnia was the criterion for introducing diurnal MIPPV, since it highlighted the inability to breathe completely unassisted during the day between 2 nights of effective nasal ventilation. Patients were discharged home after 2 learning days in the hospital. In the present study, patients were prospectively included and studied since they presented diurnal hypercapnia despite nocturnal NIPPV. Data when starting nocturnal NIPPV were retrospectively retrieved. Pure bulbar muscle dysfunction was an exclusion criterion for starting MIPPV, but decrease in swallowing speed was not.

\section{Monitoring and equipment}

$\mathrm{Pt}_{\mathrm{t}, \mathrm{CO}_{2}}$ was noninvasively recorded (TCM3 ${ }_{\mathbb{R}}$; Radiometer, Copenhagen, Denmark). The best of three vital capacities (VC) was recorded. The spontaneous respiratory rate, tidal
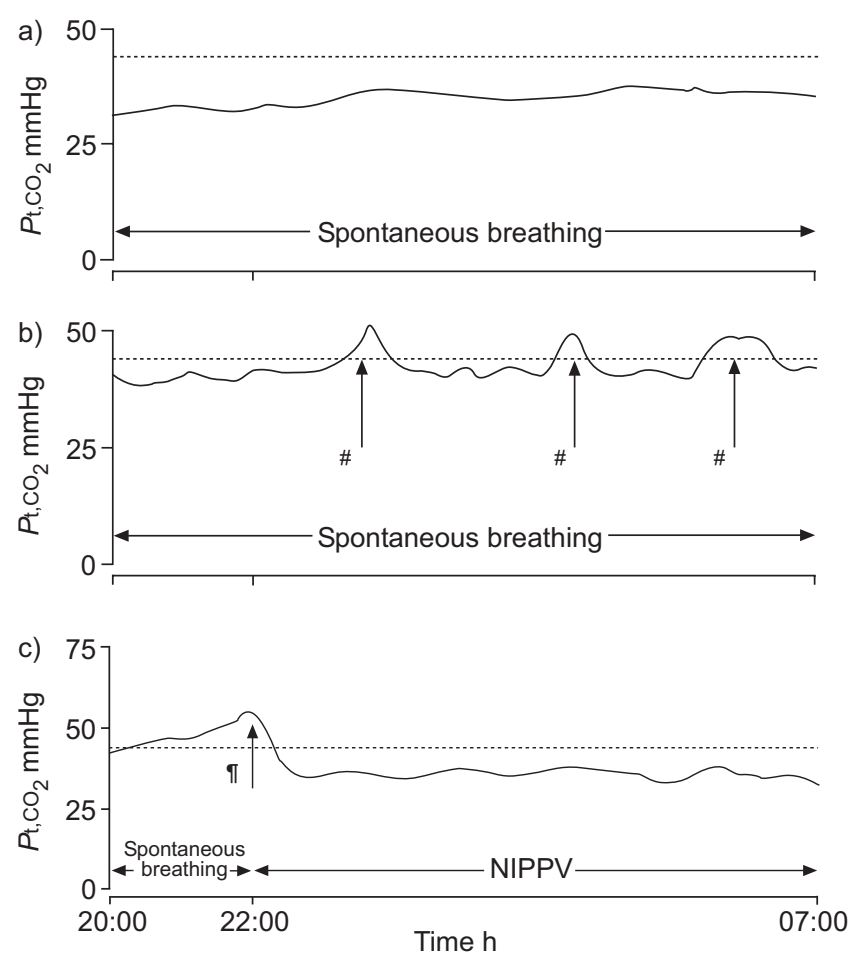

FIGURE 1. Schematic transcutaneous carbon dioxide tension $\left(P \mathrm{t}, \mathrm{CO}_{2}\right)$ monitoring at the time of inclusion in a) spontaneous ventilation (stage 0), b) at the start of nocturnal intermittent positive pressure ventilation (NIPPV; stage 1), and c) at the start of mouthpiece intermittent positive pressure ventilation (stage 2). ..... $P \mathrm{t}, \mathrm{CO}_{2}=5.98 \mathrm{kPa}$. ${ }^{\#}$ : sleep-related $P \mathrm{t}, \mathrm{CO}_{2}>5.98 \mathrm{kPa} ; "$ : end-diurnal $P \mathrm{t}, \mathrm{CO}_{2}>5.98 \mathrm{kPa}$ $0.133 \mathrm{kPa}=1 \mathrm{mmHg}$.

volume and minute ventilation at rest were averaged over a full $1 \mathrm{~min}$ of quiet breathing (5410; Ohmeda Medical, Louisville, KY, USA). Predicted values for VC were calculated using reference values proposed by the European Respiratory Society [15]. Maximal inspiratory pressure (MIP) was measured according to the technique of BLACK and HYATT [16] (Microloop ${ }^{\circledR}$; Micro Medical Ltd, Rochester, UK). Alveolar minute ventilation was calculated by the technique of HARRIS et al. [17]. Patients were asked to confirm the presence (1 point) or the absence ( 0 point) of seven respiratory-linked symptoms, which were: 1) chronic secretions; 2) dyspnoea; 3) loss of appetite and weight; 4) depression; 5) intellectual fatigue or trouble of concentration; 6) headaches; and 7) swallowing troubles [18]. A score of seven out of seven points was given for seven present symptoms and a score of zero out of seven was given if no symptom was present. Symptoms were quoted when starting MIPPV and $1 \mathrm{yr}$ later. $\mathrm{Pt}_{\mathrm{t}} \mathrm{CO}_{2}$ and symptom scores were not recorded during the day when nocturnal NIPPV started. Free time was recorded as the maximal time in one continuous shot of unassisted breath per $24 \mathrm{~h}$.

\section{Mouthpiece ventilation}

The rigid plastic-made mouthpiece (Mouthpiece angled; Respironics, Murrysville, PA, USA) was inserted into short tubing held by a rigid acrylonitrile butadiene styrene (ABS) piece constructed by G. Wasteels (fig. 2). ABS support is placed on patients' shoulders aiming at following body movements. This self-supporting system should ensure the stability of the 


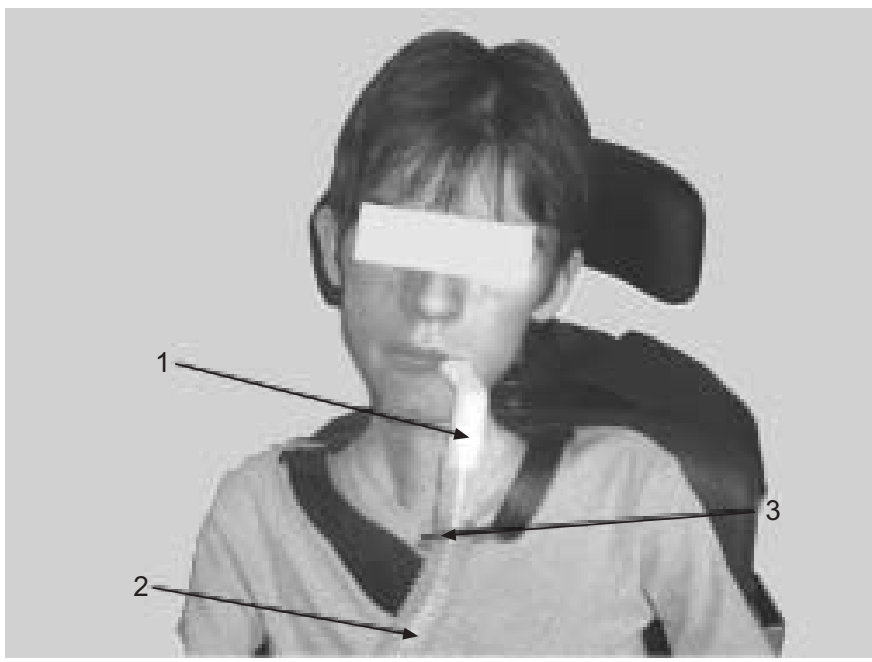

FIGURE 2. Diagram showing the mouthpiece self-supporting system. 1) Rigid plastic mouthpiece; 2) short tubing; 3) fixation on the shoulders.

mouthpiece, even when the patient does not hold it in their mouth. Volumetric ventilators, also used for the NIPPV, were placed with an additional battery on the wheelchair: 15 Eole3 (Saime, Savigny le Temple, France), 12 PLV100 (Lifecare, Lafayette, LA, USA), 1 Legendair and 6 Airox Home 1 (BIO MS, Pau, France), 4 EV801 (Dräger, Lübeck, Germany), and 4 Breas PV501 (Breas, Molnlycke, Sweden).

\section{Analysis}

Survival was calculated by Kaplan-Meier analysis (Medcalc ${ }^{\circledR}$; Medcalc software, Mariakerke, Belgium). Lung function and body characteristics were compared by ANOVA. A student Newman-Keuls test was used for all post-ANOVA comparisons between NIPPV, MIPPV and 1, 3, 5 and 7 yrs MIPPV follow-up. Paired t-tests compared diurnal $\mathrm{Pt}_{\mathrm{t}, \mathrm{CO}_{2}}$ and symptom scores before and after MIPPV. Significance was accepted for $\mathrm{p}<0.05$.

\section{RESULTS}

MIPPV started $4.1 \pm 2.5$ yrs after NIPPV implementation. Figure 3 shows 1-, 3-, 5- and 7-yr MIPPV survival rates reaching 88, 77, 58 and 51\%, respectively. Patients' characteristics are presented in table 1. Lung function significantly lowered between NIPPV and MIPPV initiations but VC was not different during the first 5 yrs with MIPPV, despite a significant decrease in MIP within 3 yrs. Figure 4 shows significant daytime $P_{\mathrm{t}, \mathrm{CO}_{2}}$ improvements with MIPPV. Normocapnia remained constant during the study. Symptoms scores decreased after establishing MIPPV. Appetite improved in seven out of 12 patients, dyspnoea disappeared in eight out of 11 and swallowing improved in six out of seven patients. In total, 11 patients died. The characteristics measured before deaths are shown in table 2 . Five patients died from cardiac failure as a result of low output syndrome, two from sudden death during the night, three from acute respiratory failure (ARF), and one patient (No. 11) underwent tracheostomy during an acute respiratory infection after using MIPPV for 2.3 yrs. The patient died from tracheal bleeding 3 months later. Among the three patients with ARF, patient No. 4 presented with a decrease in swallowing speed. The patient died at home after $1.6 \mathrm{yrs}$ of MIPPV from pneumonia as bulbar weakness developed. Patient No. 5 dramatically lost weight and became very weak, dying at home during a chest infection. Patient No. 7 died after 2.1 yrs of MIPPV during an emergency tracheal endoscopy. Since assisted cough by manual chest compression was ineffective in patient Nos 4, 5 and 7 (table 2), the current authors believe that these patients probably could have been helped if the Cough-Assist ${ }^{\circledR}$ device had been available in Europe before

TABLE 1 Characteristics by ventilation stages with spirometric data after 1, 3, 5 and 7 yrs of follow-up

\begin{tabular}{|c|c|c|c|c|c|c|c|}
\hline Subjects $n$ & 42 & 42 & 35 & 28 & 17 & 13 & \\
\hline Height $\mathbf{c m}$ & $164 \pm 8$ & $164 \pm 8$ & $163 \pm 8$ & $163 \pm 8$ & $163 \pm 8$ & $164 \pm 8$ & \\
\hline Weight kg & $52 \pm 15$ & $47 \pm 16$ & $49 \pm 13$ & $49 \pm 13$ & $47 \pm 11$ & $46 \pm 12$ & \\
\hline BMI & $19.2 \pm 4.5$ & $17.6 \pm 5.2$ & $18.5 \pm 4.3$ & $18.3 \pm 4.5$ & $17.7 \pm 4.0$ & $17.1 \pm 4.5$ & \\
\hline MIP $\mathrm{cmH}_{2} \mathrm{O}^{\star * *}$ & $29 \pm 11$ & $16 \pm 5$ & $15 \pm 5$ & $12 \pm 5$ & $8 \pm 3$ & $6 \pm 2$ & $\mathrm{a}, \mathrm{c}, \mathrm{d}, \mathrm{e}$ \\
\hline$V^{\prime} T \mathrm{~mL}^{\star \star \star \star}$ & $281 \pm 87$ & $217 \pm 64$ & $199 \pm 46$ & $181 \pm 57$ & $168 \pm 58$ & $137 \pm 75$ & $\mathrm{a}, \mathrm{e}$ \\
\hline $\mathbf{R R} \cdot \mathrm{mL}^{-1 \#}$ & $21 \pm 5$ & $24 \pm 6$ & $24 \pm 5$ & $25 \pm 6$ & $26 \pm 6$ & $26 \pm 5$ & a \\
\hline$V^{\prime} E \mathrm{~mL}^{\star \star * *}$ & $5692 \pm 1657$ & $5027 \pm 1339$ & $4688 \pm 1271$ & $4466 \pm 1525$ & $4292 \pm 1458$ & $3396 \pm 1772$ & $\mathrm{a}, \mathrm{e}$ \\
\hline$V^{\prime}$ E,alv $m L^{* * *}$ & $3398 \pm 1058$ & $2792 \pm 916$ & $2509 \pm 848$ & $2263 \pm 1011$ & $2057 \pm 1112$ & $1391 \pm 1278$ & $a, e, f$ \\
\hline
\end{tabular}

Data are presented as mean \pm SD, unless otherwise stated. NIPPV: start of nocturnal nasal intermittent positive pressure ventilation; MIPPV: start of diurnal mouthpiece intermittent positive pressure ventilation; BMI: body mass index; VC: vital capacity; \% pred: percentage of predicted; MIP: maximal inspiratory pressure; $V$ 'T: tidal volume; RR: respiratory rate; V'E: spontaneous minute expiratory ventilation; V'E,alv: alveolar minute ventilation; $\mathrm{Pt}_{\mathrm{t}} \mathrm{CO}_{2}$ : transcutaceous $\mathrm{CO}_{2}$ tension; a: NIPPV/MIPPV; b: MIPPV/1 yr; c: MIPPV/3 yrs; d: MIPPV/5 yrs; e: MIPPV/7 yrs; f: 1 yr/7 yrs. ${ }^{*}: p=0.005 ;{ }^{*} *$ : $p<0.001 .1 \mathrm{mmHg}=0.133 \mathrm{kPa}$. 


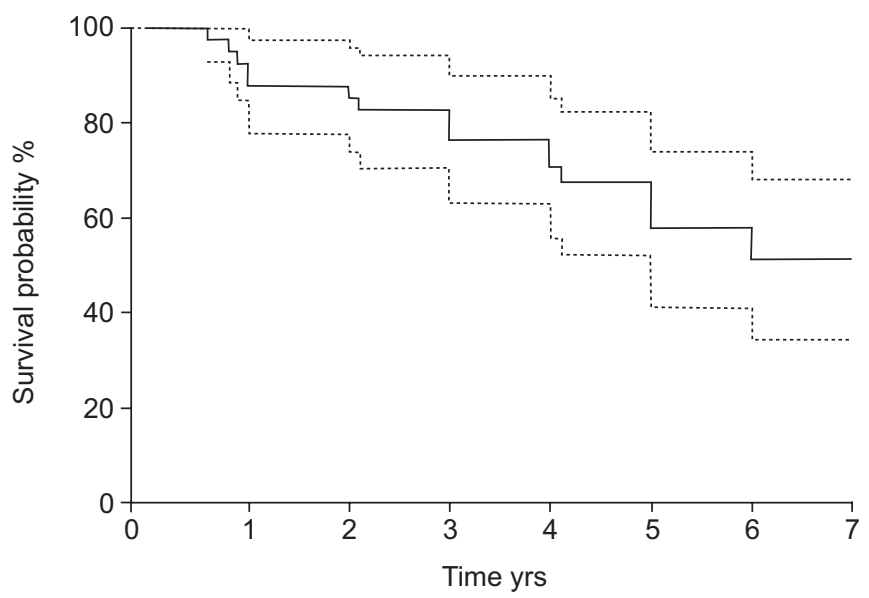

FIGURE 3. Survival curve (including $95 \%$ confidence interval) of daytime ventilation via mouthpiece in Duchenne patients. —: survival curve; $\cdots .$. : upper and lower limits of $95 \%$ confidence interval.

2002. In the present authors' experience, Cough-assist ${ }_{\circledR}$ is effective in $\pm 80 \%$ of the subjects in whom manual cough techniques have become useless. The loss of mouthpiece out of the mouth did not result in additional adverse events. Assistcontrol mode of ventilation was used in 39 patients and control mode in three patients. Ventilator setting remained the same during night and day. Ventilator mean frequency was $19 \pm 3$ rates $\cdot \mathrm{min}^{-1}$ and the mean tidal volume was $688 \pm 19 \mathrm{~mL}$.

\section{DISCUSSION}

In the long term, daytime mouthpiece ventilation provided $50 \%$ survival at 31 yrs of age and stabilised lung function for 5 yrs in DMD patients reaching diurnal hypercapnia after 4.1 yrs NIPPV. In the short term, $\mathrm{Pt}_{\mathrm{t}} \mathrm{CO}_{2}$ and symptoms scores improved. Although an open study, the current results demonstrate that mouthpiece interface is an option to ventilate DMD patients during the day. These results are difficult to compare with controlled tracheostomised groups because the indications and clinical conditions for tracheostomy are not the same as for MIPPV [19]. In the present authors' experience, since patients were well informed about mouthpiece technology, they all chose MIPPV instead of daytime ventilation via nasal mask [20] or via tracheostomy [21].

\section{Impact on survival}

The present inception cohort study analysed DMD patients at a later stage of disease progression than previously published studies, i.e. the diurnal hypercapnia stage. This stage is logically expected after a period of several years with nocturnal NIPPV $[5,19,20]$. This specific context makes historical comparisons difficult.

In DMD, survival without mechanical assistance was consistently reported at the beginning of the third decade of life (19.3 yrs [20], 20 yrs [22] and 21 yrs [23]). Undoubtedly, NIPPV has been an important advance in prolonging life. Previous studies related spectacular improvement in DMD survival probability with NIPPV confined to the night only. The studies by EAGLE et al. [20] and YASUMA et al. [24] reported 50\% survival at 25.3 and 30.4 yrs, respectively. Despite being retrospective, these NIPPV studies are interesting since they considered all DMD patients from birth, even those not reaching the criterion for starting mechanical ventilation. Using similar parameters, the present data are comparable with those of SIMONDS et al. [10] and $\mathrm{BACH}$ [25]. In the latter, similar techniques of ventilation were used (volumetric respirators, nasal mask plus mouthpiece, night-time and daytime ventilation) in a similar DMD population. Those patients started nocturnal ventilation at a similar age of 18.6 versus 19.4 yrs in the present study. The mean $(50 \%)$ survival age was 26.4 versus 32.5 yrs. The

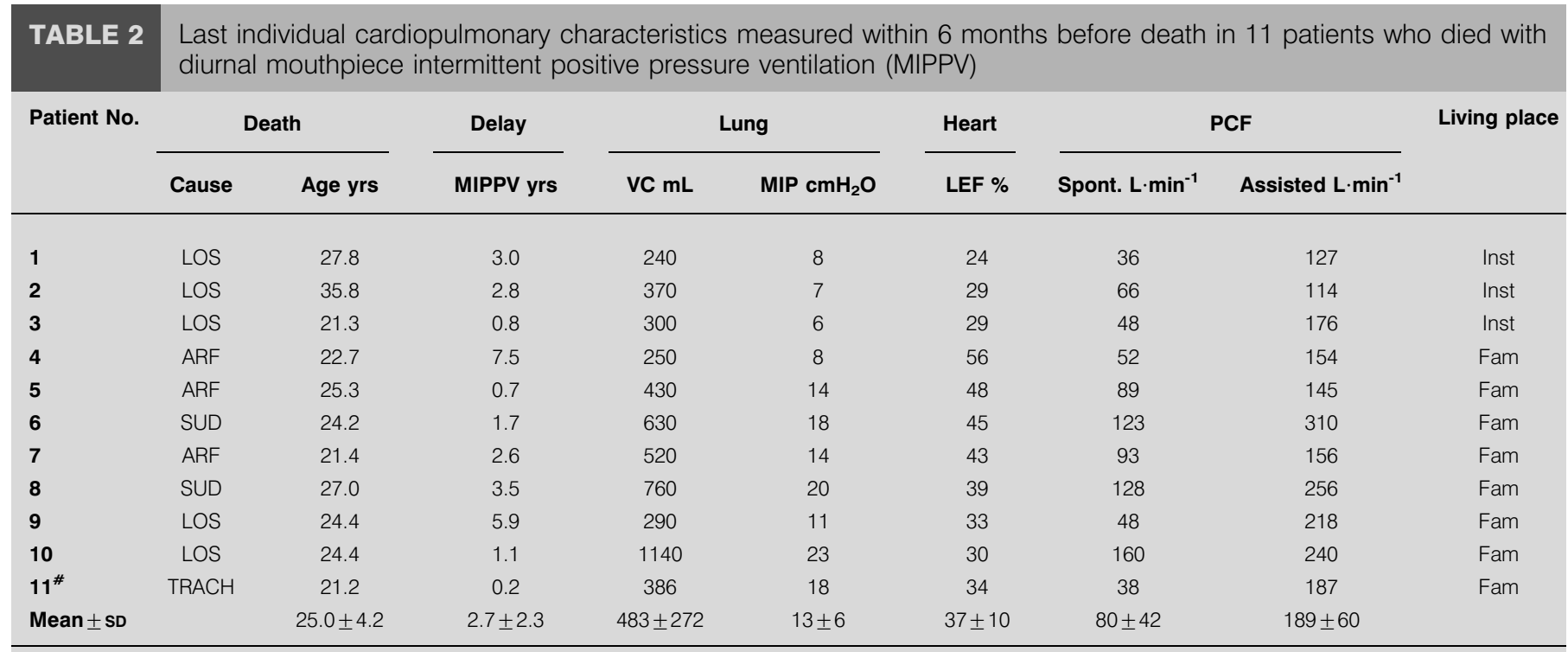

VC: vital capacity; MIP: maximal inspiratory pressure; LEF: left ejection fraction; PCF: peak cough flows, measured spontaneously (Spont.) and assisted (Assisted) with air-stacking combined with manual chest compression; LOS: Iow output syndrome; ARF: acute respiratory failure; SUD: sudden death; TRACH: tracheostomy complication; Inst: living in institution; Fam: living with family; *: patient undergoing tracheostomy. 


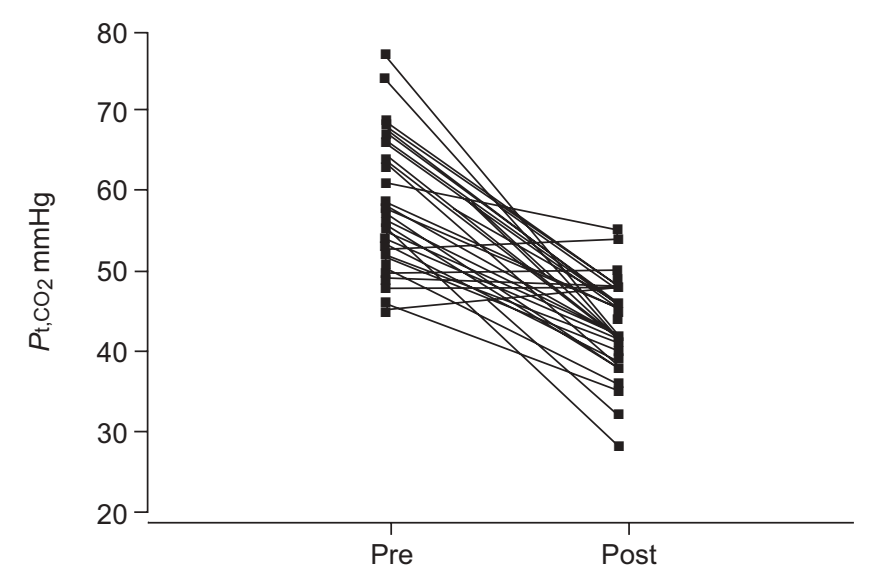

FIGURE 4. Impact of daytime ventilation via mouthpiece on transcutaneous carbon dioxide tension $\left(\mathrm{Pt}_{\mathrm{t}} \mathrm{CO}_{2}\right)$ before (pre) and $>6$ months after (post) starting daytime mouthpiece ventilation.

proportion of survivors aged $>25$ yrs was 75 versus $83 \%$. The mean use of NIPPV plus MIPPV was 7.8 versus $8.6 \mathrm{yrs}$ in the current study. The comparison of the current data with those of SIMONDS et al. [10] is instructive. In both studies, patients were ventilated at the point of diurnal hypercapnia measured by $P_{t}, C_{2}$, but in the study by SIMONDS et al. [10] patients started nocturnal NIPPV when they would have been offered diurnal MIPPV in the present study. Interestingly, the 5 -yr survival was $70 \%$ in both studies. However, important differences distinguish the current study from that of SIMONDS et al. [10]. First, in the current study, nocturnal NIPPV was established earlier (at nocturnal hypercapnia) than in the study of SIMONDS et al. [10] (at diurnal hypercapnia). Recent data from the same group confirm the appropriateness of the early approach [14]. Secondly, the natural illness evolution of the patients in the study of SIMONDS et al. [10] seemed clearly more severe than in the present study, perhaps related to the absence of early assisted ventilation. In the study of SIMONDS et al. [10], NIPPV was implemented at very low VCs (range 0-600 versus 240-1,240 mL in the current study), with diurnal $P_{\mathrm{t}}, \mathrm{CO}_{2}$ at 10.24 versus $8.24 \mathrm{kPa}$. In the present study, delayed diurnal hypercapnia at higher VC suggests a slower deterioration of the respiratory function with earlier NIPPV.

The $50 \%$ survival was 31 yrs. The average age of 32.5 yrs among those patients using MIPPV for $\geqslant 7$ yrs suggests that MIPPV prolonged life. This is important because NIPPV is now considered so effective [19] that almost three out of four DMD patients are expected to survive for $\geqslant 5$ yrs with NIPPV [10], giving them the chance to prolong life to later and unexplored respiratory stages than previously investigated. In the current study, $64 \%$ patients died from cardiac failure (table 2). This confirms that cardiac failure represents the major cause of death in DMD patients with prolonged ventilation. All the patients with cardiomyopathy were treated with $\beta$-blockers and angiotensin-converting enzyme inhibitors when the left ejection fraction was $<50 \%$. Perhaps here the widespread use of cardiac medications improved cardiac management and could influence the survival rate of the present DMD population.
The living place did not differ greatly between 11 out of the 42 dead patients versus 31 out of the 42 survivors. Of these, 27 versus $19 \%$ lived in an institution, 73 versus $71 \%$ lived at home, and 0 versus $10 \%$ lived in a nursing home. This clearly illustrates the difficulty of all ventilated patients in staying at home because of the lack of financial and family-based resources.

\section{Impact on lung function}

Deterioration in respiratory function is related to muscle strength [23]. In DMD patients, VC is reported to decline at a higher rate in the last years of life [26]. Interestingly, VC was previously reported to decline less [27] or even to stabilise [28] with NIPPV. In the present study, the annual decline of VC was $118 \mathrm{~mL}$ with nocturnal NIPPV. As a similar result, VC stabilised for $>5 \mathrm{yrs}$ with daytime MIPPV (decline of $24 \mathrm{~mL} \cdot \mathrm{yr}^{-1}$; nonsignificant) despite significant decline in MIP within 3 yrs. Lowering VC decrease can be explained by resting respiratory muscle or by reducing mechanical load, but, up to now, no data are available to confirm these hypotheses. Anyway, reducing the impact of the disease progression on lung function is of clinical importance in ventilator-free time preservation in the long term. A free time of as little as 3060 min makes sense in the management of these patients, their families and caregivers. It provides ventilator-free autonomy for daily activities, such as transfer from the bed to the wheelchair/toilets, taking a bath or a shower, and drinking or eating without respiratory mechanical support. It also reduces the fear of suffocating in case of ventilator failure, which is not negligible.

\section{Impact on diurnal hypercapnia}

In the current study, MIPPV significantly improved enddiurnal $\mathrm{CO}_{2}$ tension (fig. 4). As similarly reported with NIPPV $[10,29]$, this improvement remained constant in the long term during the full follow-up for all the subjects with arterial

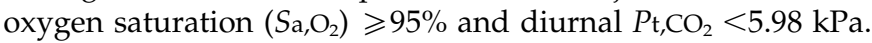

\section{Impact on the symptoms}

In 1999, after the present study started, the American Thoracic Society (ATS) proposed a constant awake carbon dioxide tension $>6.65 \mathrm{kPa}$ and/or $\mathrm{Sa}_{2} \mathrm{O}_{2}<92 \%$ in restrictive disorders as a criterion to start diurnal ventilation when nocturnal NIPPV is not sufficient [5]. In the current study, no patient met the "a posteriori" ATS criteria. The patients were soon included for starting diurnal ventilation since they presented with a diurnal $\mathrm{Pt}_{\mathrm{t}, \mathrm{CO}_{2}}$ of $>5.98 \mathrm{kPa}$. At present, the current authors observed that symptoms were already present in 40 out of 42 patients and that a symptom score higher or equal to three out of seven was found in 27 out of 42 patients. The presence of the symptoms suggests physiological changes along with impending need for additional daytime ventilation. Symptoms perhaps signal the presence of a high cost of energy expenditure spent in maintaining normocapnia, probably leading to further clinical deterioration. This hypothesis, however, needs further investigation. As it was demonstrated with NIPPV, DMD patients may benefit from daytime ventilation before further worsening [14]. However, controlled investigations are needed to help clinicians in deciding when to start daytime ventilation, perhaps by the use of a simple symptom score. To the current authors' surprise, swallowing 
problems and aspirations were reversible in six out of seven patients despite initially looking like bulbar impairment. This temporary recovery suggests that swallowing problems were related to the respiratory worsening rather than to pure bulbar involvement. In such similar cases, the current authors strongly recommend a trial with mouthpiece ventilation before considering tracheostomy. Compared with previous studies reporting $>30 \%$ DMD patients disrupting NIPPV for tracheostomy [29], two (5\%) patients were candidates for tracheostomy in the present study.

\section{Mouthpiece safety and tolerance}

In very weak DMD patients, it was thought that the risk of releasing the mouthpiece due to orbicularis oris muscle weakness [5] was so important that MIPPV safety was uncertain. The current study contradicts this view and demonstrates that appropriate self-supporting system minimises efforts to hold the piece and prevents accidents due to disconnection (fig. 2). Leaks around the mouth were largely present, but patients knowingly controlled the leaks and pursed the lips at regular intervals (once every two or three breaths, sometimes only twice per minute) as they felt it necessary to be fully inflated in response to their needs. For a prolonged period of release, patients hold their mouthpiece in contact with their cheek to avoid low pressure alarm. No patient, except patient No. 2, presented with orthodontic disorders. This contradicts another experience reported after prolonged use of the mouthpiece [8].

With tracheostomy and nasal ventilation, patients are expected to take air at each insufflation. With a diurnal mouthpiece, the present authors observed that patients managed ventilation differently. When starting MIPPV, some patients took air once on four insufflations and this proportion increased with disease progression. Others took air at each insufflation, but they produced voluntary massive inspiratory leaks. The patients pursed the lips once or twice per minute. With illness progression, the patients decreased the quantity of leaks and increased the frequency of lip pursing. This finding means that recording the ventilator's clock alone may provide incorrect information on how patients are ventilated. For this reason, the only method to assess the free time is to stop ventilation and to record how long the patients can breathe without the machine. In practice, patients were questioned on the time they could breathe unassisted and were invited to demonstrate this. The test was stopped when patients expressed the need to start ventilation again. The majority of the patients could not reach $\mathrm{O}_{2}$ desaturation in the trial. At the time of study inclusion, MIPPV was prescribed for $2 \mathrm{~h}$ after lunch, and patients were asked to progressively increase ventilation support. As shown in table 1, the surprising finding was that patients naturally spend more time with the respirator than prescribed and, thus, MIPPV was found to be addictive for most of them. This can be explained for the reasons described previously. Nevertheless, the current authors changed the approach and are now looking to achieve improved compliance with the precription.

\section{Conclusion}

In conclusion, mouthpiece ventilation during the day as an extension of nocturnal ventilation is safe and provides reliable survival in end-stage Duchenne muscular dystrophy patients.
These patients benefit from the treatment as judged by release of diurnal hypercapnia, improvement of the major respiratoryrelated symptoms, and by long-term vital capacity stabilisation. Daytime ventilation via a mouthpiece can be recommended on the condition that patients are equipped with a self-supporting harness around the neck, and that they can accede to noninvasive techniques for airway clearance.

\section{ACKNOWLEDGEMENTS}

The authors would like to thank T. Troosters (Katholieke Universiteit Leuven, Belgium) and D. de Guigné (Moulins, France) for their friendly help.

\section{REFERENCES}

1 Smith PE, Edwards RH, Calverley PM. Ventilation and breathing pattern during sleep in Duchenne muscular dystrophy. Chest 1989; 96: 1346-1351.

2 Lyager S, Steffensen B, Juhl B. Indicators of need for mechanical ventilation in Duchenne muscular dystrophy and spinal muscular atrophy. Chest 1995; 108: 779-785.

3 Chailleux E, Fauroux B, Binet F, Dautzenberg B, Polu J-M. Predictors of survival in patients receiving domiciliary oxygen therapy or mechanical ventilation. Chest 1996; 109: 741-749.

4 Robert D, Willig TN, Leger P, Paulus J. Long-term nasal ventilation in neuromuscular disorders: report of a consensus conference. Eur Respir J 1993; 6: 599-606.

5 Clinical indications for noninvasive positive pressure ventilation in chronic respiratory failure due to restrictive lung disease, COPD, and nocturnal hypoventilation: a consensus conference report. Chest 1999; 116: 521-534.

6 Bach JR, Alba AS, Saporito LR. Intermittent positive pressure ventilation via the mouth as an alternative to tracheostomy for 257 ventilators users. Chest 1993; 103: 174-182.

7 Bach JR. A comparison of long-term ventilatory support alternatives from the perspective of the patient and care giver. Chest 1993; 104: 1702-1706.

8 Bach JR, O'Brien J, Krotenberg R, Alba AS. Management of end stage respiratory failure in Duchenne muscular dystrophy. Muscle Nerve 1987; 10: 177-182.

9 Dean S, Bach JR. The use of noninvasive respiratory muscle aids in the management of patients with progressive neuromuscular diseases. Respir Care Clin N Am 1996; 2: 223-240.

10 Simonds AK, Muntoni F, Heather S, Fielding S. Impact of nasal ventilation on survival in hypercapnic Duchenne muscular dystrophy. Thorax 1998; 53: 949-952.

11 Bakker E, Jennekens FGI, de Visser M, Wintzen AR. Duchenne and Becker muscular dystrophies. In: Emery AEH, ed. Diagnostic for Neuromuscular Disorders. London, Royal Society of Medicine Press, 1997; pp. 1-4.

12 Toussaint M, De Win H, Steens M, Soudon P. Effect of intrapulmonary percussive ventilation on mucus clearance in Duchenne muscular dystrophy patients: a preliminary report. Respir Care 2003; 48: 940-947.

13 Soudon P, Wouters A, Kulakowski S. pO2-pCO2 Transcutaneous monitoring during sleep and ventilatory function in X-linked progressive muscular dystrophies. Cardiomyology 1984; 3: 21-38. 
14 Ward S, Chatwin M, Heather S, Simonds AK. Randomised controlled trial of non-invasive ventilation (NIV) for nocturnal hypoventilation in neuromuscular and chest wall disease patients with daytime normocapnia. Thorax 2005; 60: 1019-1024.

15 Quanjer PH, Tammeling GJ, Cotes JE, Pederson OF, Peslin R, Yernault JC. Lung volumes and forced ventilatory flows. Report working party standardization of lung function tests, European community for steel and coal. Official statement of the European Respiratory Society. Eur Respir J 1993; 6: Suppl. 16, 5-40.

16 Black LF, Hyatt RE. Maximal respiratory pressures: normal values and relationship to age and sex. Am Rev Respir Dis 1969; 99: 696-702.

17 Harris EA, Seelye ER, Whitlock RM. Revised standards for normal resting dead-space volume and venous admixture in men and women. Clin Sci Mol Med 1978; 55: 125-128.

18 Mellies U, Ragette R, Dohna Schwake C, Boehm H, Voit T, Teschler H. Daytime predictors of sleep disordered breathing in children and adolescents with neuromuscular disorders. Neuromuscul Disord 2003; 13: 123-128.

19 Simonds AK. Home ventilation. Eur Respir J 2003; 22: Suppl. 47, 38S-46S.

20 Eagle M, Baudoin SV, Chandler C, Giddings DR, Bullock R, Bushby K. Survival in Duchenne muscular dystrophy: improvements in life expectancy since 1967 and the impact of home nocturnal ventilation. Neuromuscul Disord 2002; 12: 926-929.

21 Baydur A, Layne E, Aral H, et al. Long term non-invasive ventilation in the community for patients with musculoskeletal disorders: 46 years experience and review. Thorax 2000; 55: 4-11.
22 Konagaya M, Sakai M, Wakayama T, Kimura S, Kuru S, Yasuma $F$. Effect of intermittent positive pressure ventilation on life-span and causes of death in Duchenne muscular dystrophy. Rinsho Shinkeigaku 2005; 45: 643-646.

23 Philipps MF, Quinlivan RCM, Edwards RHT, Calverley PMA. Changes in spirometry over time as a prognostic marker in patients with Duchenne muscular dystrophy. Am J Respir Crit Care Med 2001; 164: 2191-2194.

24 Yasuma F, Sakai M, Matsuoka Y. Effects of noninvasive ventilation on survival in patients with Duchenne's muscular dystrophy. Chest 1996; 109: 590.

25 Bach JR. Management of neuromuscular ventilatory failure by 24 hour noninvasive intermittent positive pressure ventilation. Eur Respir Rev 1993; 3: 284-291.

26 Baydur A, Gilgoff I, Prentice W, Carlson M, Fischer DA. Decline in respiratory function and experience with longterm assisted ventilation in advanced Duchenne's muscular dystrophy. Chest 1990; 97: 884-889.

27 Vianello A, Bevilacqua M, Salvador V, Cardaioli C, Vincenti E. Long-term nasal intermittent positive ventilation in advanced Duchenne's muscular dystrophy. Chest 1994; 105: 445-448.

28 Annane D, Quera-Salva MA, Lofaso F, et al. Mechanisms underlying effects of nocturnal ventilation on daytime blood gases in neuromuscular diseases. Eur Respir J 1999; 13: 157-162.

29 Leger P, Bedicam JM, Cornette A, et al. Nasal intermittent positive pressure ventilation: long-term follow-up in patients with severe chronic respiratory insufficiency. Chest 1994; 105: 100-105. 